\title{
RESEARCH
}

Open Access

\section{Effect of moderate hypothermic circulatory arrest on neurological outcomes in elderly patients undergoing replacement of the thoracic aorta}

Mohamed Salem º, Christine Friedrich, Alexander Thiem, Mostafa Ahmed Salem, Thomas Puehler, Rene Rusch, Rouven Berndt, Jochen Cremer and Assad Haneya

\begin{abstract}
Background: Various studies evaluated the relationship between hypothermic circulatory arrest and neurological outcome in patients undergoing replacement of ascending aorta. The current analysis focuses on the effect of moderate hypothermic circulatory arrest (MHCA) on elderly patients. The aim of our study was to evaluate the impact of MHCA on neurological outcomes in elderly patients undergoing replacement of the ascending aorta.

Results: We retrospectively analyzed 905 consecutive patients, who underwent elective replacement of ascending aorta in MHCA ( $24 \pm 2^{\circ} \mathrm{C}$, nasopharyngeal) between 2001 and 2015. Patients with acute aortic dissection were excluded from this study. Patients were divided into two groups: those aged 75 years and older (elderly group $22.4 \%, n=203$ ) and those younger than 75 years (younger group $77.6 \%, n=702$ ).

The average age was $63.2 \pm 10.2$ in the young group vs. $78.7 \pm 3.0$ years in elderly group $(p<0.001)$. The elderly group had a significantly higher EuroSCORE II [26.7\% $(18.1,36.3)$ vs. $11.6 \%(7.4,19.9) ; p<0.001)]$. The incidence of coronary heart disease $(49.8 \%$ vs. $35.6 \%, p<0.001)$ and chronic renal failure $(17.2 \%$ vs. $9.1 \%, p=0.001)$ was significantly higher in the elderly group. Intraoperatively, the time of MHCA $[14 \min (12,17)$ vs. $15 \min (12,18) ; p=$ $0.42]$, cardiopulmonary bypass $[139 \mathrm{~min}(110,183)$ vs. $144 \mathrm{~min}(113,189) ; p=0.225]$, and cross-clamping $[91 \mathrm{~min}(63$, 116) vs. 92 min $(65,127) ; p=0.348]$ was similar in both groups. Postoperatively, a higher incidence of delirium was significantly reported in the elderly group $(24.1 \%$ vs. $9.0 \%, p<0.001)$. However, there was no significant difference regarding neurological complications between both groups. A 30-day mortality was acceptable for the elderly group, but significantly higher compared with the younger group ( $7.1 \%$ vs. $3.5 \%, p=0.031)$.
\end{abstract}

Conclusions: Our study suggests that surgical replacement of the ascending aorta in MHCA can also be applied safely in elderly patients without increasing the risk of severe neurological complications.

Keywords: Stroke in cardiac patient, Ascending aorta, Hypothermic circulatory arrest

\footnotetext{
* Correspondence: drmohsalem83@hotmail.com; mohamed.salem@uksh.de Department of Cardiovascular Surgery, University Hospital of

Schleswig-Holstein, Campus Kiel, Arnold-Heller-Straße 3, 24105 Kiel, Germany
} 


\section{Background}

Replacement of the ascending aorta due to calcification and aneurysm is a major concern in cardiovascular surgery and is associated with a high risk of neurological complications [1]. Cerebral protection during this procedure is considered a major concern in successful thoracic aortic surgery due to its direct impact on the postoperative prognosis [2]. Beside antegrade and retrograde cerebral perfusion, MHCA is considered as one of the most preferred and successful methods to lower oxygen consumption and avoid brain tissue injury during the surgical replacement of the ascending aorta.

Various studies were carried out to analyze the effect of each method on postoperative neurological outcome. However, there is still a huge debate between cardiovascular surgeons regarding the best method of protecting the cerebral tissue during the duration of circulatory arrest.

The hypothermic circulatory arrest is considered the established technique for cerebral tissue protection during the surgical procedure of the ascending aorta and aortic arch due to its easy and safe application compared with antegrade and retrograde cerebral perfusion which is associated with various limitations [3].

Due to the marked increase in life expectancy, the number of patients over 75 years who undergo such a kind of operations also increases due to various medical and political considerations [4]. Various studies were done to figure out the relationship between the hypothermic circulatory arrest and the postoperative neurological outcome in general. In our analysis, we focused on the effect of MHCA on elderly patients more than 75 years old undergoing replacement of ascending aorta in comparison to younger patients regarding the postoperative neurological outcome.

In the current analysis, we studied the effect of MHCA during the replacement of the ascending aorta on the elderly patients.

\section{Methods}

\section{Patient population}

This is a retrospective study, enclosing 905 consecutive patients who underwent replacement of the ascending aorta due to calcification or aneurysm using MHCA $\left(24 \pm 2{ }^{\circ} \mathrm{C}\right.$, nasopharyngeal) in our center till 2015 , either isolated or combined with other procedures (coronary artery bypass grafting, valve replacement, etc.). Patients with aortic dissection, as well as patients with redo operations and missed follow-up, were excluded from the study (Fig. 1).

Patients were divided into two groups: those aged 75 years and older (elderly group, 22.4\%) and those younger than 75 years (younger group, 77.6\%). The limit whether older or younger than 75 years old was settled according to a study from Friedrich et al. (2007), which in collaboration with the German Federal Quality Assurance Office (Bundesgeschäftsstelle Qualitätssicherung, BQS) analyzed the risk profiles of elderly patients by means of data sets from all cardiac surgical centers in Germany for the year 2007. The results showed that those patients over age 75 had significantly more prognosis-determining comorbidities and risk factors with higher complication rates and mortality compared to patients younger in age (e.g., a 4.3-fold risk elevation for renal failure, a 3.0-fold elevation for neurological adverse outcomes, and 3.7-fold elevation for inhospital mortality) [4].

The primary endpoint was the postoperative neurologic complications. Secondary endpoints were a 30-day mortality and postoperative course of various body organs (e.g., ventilation time, bleeding, acute renal failure).

Data were collected and extracted from the institution's database and from medical records. The study protocol was approved by the local Ethics Committee in Kiel, Germany (D417/17), and the necessary individual patient consent was obtained during the hospital stay.

\section{Patient management}

Calcification or aneurysm of the ascending aorta was diagnosed either during routine X-ray investigation showing severe calcification of ascending aorta, routine echocardiographic assessment, or during coronary angiography prior to other cardiac surgery. The aortic calcification was also diagnosed and detected intraoperatively during other elective cardiac surgery such as CABG or aortic valve replacement within the direct palpation of the aorta. The decision to replace the ascending aorta was taken due to the inability of cross-clamping of the aorta due to the extensive calcification. When calcification of the ascending aorta was suspected preoperatively, a non-contrast computed tomography (CT-scan) was performed to present the exact location and extension of calcification. All patients were questioned at hospital admission for any history of neurological events as stroke or transient ischemic attack (TIA) as well as the presence of any medical records from the neurologist, computed tomography or magnetic resonance imaging. Patients were well investigated for neurological symptoms and signs, and any findings were documented on the admission sheet for further use. Without any exclusion, all patients were investigated for carotid arteries stenosis through carotid Doppler sonography. If there is a stenosis over $50-60 \%$, a CT carotid artery angiography was carried out preoperatively and a vascular surgical consultant was contacted, to prove the indication of further surgical intervention.

One of the strict criteria in the data assembly postoperatively was that the neurological adverse outcome should be of new onset after the surgical procedure and not documented in the preoperative admission sheet. 


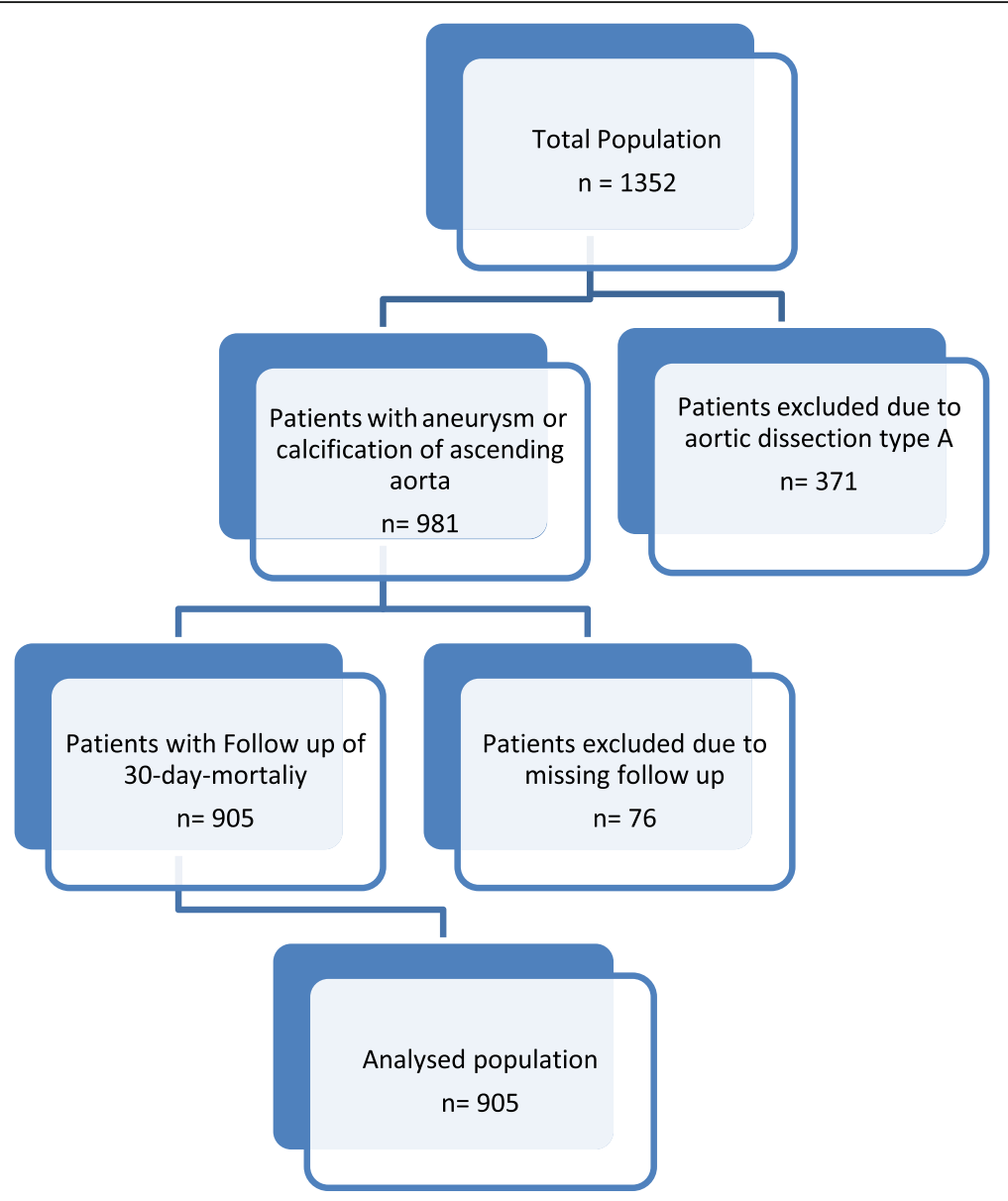

Fig. 1 Consort diagram of the total population with exclusion

The monitoring of tissue oxygenation of cerebrum intraoperatively was carried out by near-infrared spectroscopy (NIRS). Postoperative neurological sensory or motor deficits, if presented, were consulted directly by a neurologist and categorized according to a wellestablished neurological assessment. The results of the assessment were documented in patients' file from the attending neurologist, followed by the head and neck computer tomography as well as, in many cases, CT angiography for the carotid arteries to estimate the extent of stroke and brain ischemia. MRI was required in some cases from the neurologists. After CT/MRI, a neurologist was consulted again for further plans. Delirium was measured by the Confusion Assessment Method (CAM) (https://www.icudelirium.org/medicalprofessionals/delirium/monitoring-delirium-in-the-icu) and was performed routinely per each shift. CAM was performed when the Richmond-Scale was more than 4. Slightly known degree of delirium was mostly resolved rapidly under saline infusion and antipsychiatry drugs. In case of sever delirium, which requires patient fixation, a psychiatrist was consulted.

\section{Surgical procedure}

All operations were performed by senior surgeons. A standard median sternotomy followed by longitudinal pericardiotomy was carried out under general anesthesia. Direct cannulation of the distal ascending aorta was used for arterial cannulation in most cases. In cases of severe calcification of ascending aorta till its arch and inability of its distal cannulation, we used the transatrial cannulation of the left ventricle via the right upper pulmonary vein as an alternative [5]. Venous drainage was performed through cannulation of the right atrium with a common two-stage venous cannula. A standard antegrade and retrograde injection of cold blood cardioplegic solution for myocardial protection was performed in all cases. The cardiopulmonary bypass (CPB) was conducted with MHCA with core temperature between $24 \pm 2{ }^{\circ} \mathrm{C}$ which was measured nasopharyngeal. Brain tissue oxygenation was monitored by near infrared spectroscopy (NIRS). After suturing of the distal anastomosis, residual air was removed by restarting retrograde perfusion via the venous cannula and followed by slow antegrade perfusion. Continuous $\mathrm{CO}_{2}$ insufflation was used as a standard for the 
cardiac de-airing. After insertion of the perfusion cannula directly in the vascular graft, CPB restarted again. After conducting the proximal anastomosis, a cardiac de-airing is carried out before opening the clamped aortic prosthesis. Transoesophageal echocardiography was performed to control the presence of residual air in the left side of the heart. During rewarming, other procedures such as CABG or valve replacement were implemented if required.

\section{Statistical analysis}

Statistical analysis was performed using the SPSS 18.0 software (SPSS, Chicago, IL, USA). Normality of continuous variables was assessed by Kolmogorow-Smirnow test. Values of continuous data are presented as mean \pm standard deviation or as median with range or interquartile range when appropriate and compared by unpaired $t$ test, whereas not normally distributed continuous were compared by Mann-Whitney $U$ test. Categorical variables are displayed as frequency distributions $(n)$ and simple percentages (\%). Univariate comparison between the groups for categorical variables was made using the $\mathrm{chi}^{2}$ test and the Fisher's exact test when appropriate. Statistical significance was considered when $p \leq 0.05$. Logistic regression analysis was used to determine the hazards ratio (HR) of risk factors upon the 30-day survival time through backward selection with Likelihood ratio. Variables included in the regression analysis were age, EuroSCORE II, aortic aneurysm, aortic calcification, COPD, coronary heart disease, chronic renal insufficiency, additional CABG, and cardiopulmonary bypass time.

\section{Results}

The average age was $63.2 \pm 10.2$ years in the young group vs.78.7 \pm 3.0 years in the elderly group $(p<0.001)$. Female gender was more frequent in the elderly group $(39.4 \%$ vs. $31.5 \%, p=0.035)$. Accordingly, the elderly group had a significantly higher EuroSCORE II than the younger group $[26.7 \%(18.1,36.3)$ vs. $11.6 \%(7.4,19.9)$; $p=<0.001)$ ]. Coronary heart disease was significantly more frequent in the elderly group $(49.8 \%$ vs. $35.6 \%, p<$ $0.001)$ with more atrial fibrillation $(23.6 \%$ vs. $16.4 \%, p=$ 0.018 ). Chronic renal failure was significantly more often in elderly group $(17.2 \%$ vs. $9.1 \%, p=0.001)$ as well as type 2 diabetes mellitus ( $16.3 \%$ vs. $10.7 \%, p=0.031)$. Patients who suffered from an aortic aneurysm represented $86.7 \%$ of the elderly group vs. $92.2 \%$ of the younger group $(p=0.017)$. Other risk factors showed no significant difference between both groups (Table 1).

The intraoperative data analysis revealed that the isolated replacement of supra-coronary ascending aorta was performed in $63.1 \%$ of the elderly group and $51.1 \%$ of the younger group. Aortic valve replacement due to either aortic valve insufficiency or stenosis was carried out in $52.2 \%$ in elderly patients vs. $50.7 \%$ in younger patients, while CABG was performed more often in the elderly $(28.6 \%$ vs. 23.4\%), however not reaching statistical significance. Partial

Table 1 Demographic data, preoperative risk factors

\begin{tabular}{|c|c|c|c|c|}
\hline & Total & $\begin{array}{l}\text { Young group } \\
702(77.6 \%)\end{array}$ & $\begin{array}{l}\text { Elderly group } \\
203(22.4 \%)\end{array}$ & $p$ value \\
\hline Mean age, years & $\begin{array}{l}66.7 \pm 11.1 \\
69.2(61.0,74.4)\end{array}$ & $\begin{array}{l}63.2 \pm 10.2 \\
66.3(57.5,70.9)\end{array}$ & $\begin{array}{l}78.7 \pm 3.0 \\
78.0(76.3,80.1)\end{array}$ & $<0.001$ \\
\hline Female gender, $n$ & $301(33.3 \%)$ & $221(31.5 \%)$ & 80 (39.4\%) & 0.035 \\
\hline Body mass index, $\mathrm{kg} / \mathrm{m}^{2}$ & $26.5(24.2,29.4)$ & $26.8(24.2,29.7)$ & $25.4(23.7,27.8)$ & $<0.001$ \\
\hline EuroSCORE ॥\% & $4.12(2.38,7.13)$ & $11.6 \%(7.4,19.9)$ & $26.7 \%(18.1,36.3)$ & $<0.001$ \\
\hline Ejection fraction, $\%$ & $64(53,70)$ & $62(51,70)$ & $65(55,70)$ & 0.622 \\
\hline Aortic aneurysm, $n$ & $823(90.9 \%)$ & 647 (92.2\%) & $176(86.7 \%)$ & 0.017 \\
\hline Diameter of aneurysm, mm & $52(50,57)$ & $52(50,56)$ & $52(49,59)$ & 0.574 \\
\hline Aortic calcification, $n$ & $113(12.5 \%)$ & $55(7.8 \%)$ & $27(13.3 \%)$ & 0.017 \\
\hline Acute myocardial infarction, $n$ & $10(1.1 \%)$ & $8(1.1 \%)$ & $2(1.0 \%)$ & 1.000 \\
\hline Diabetes mellitus type $\|, n$ & $108(11.9 \%)$ & $75(10.7 \%)$ & $33(16.3 \%)$ & 0.031 \\
\hline Peripheral vascular disease, $n$ & $108(11.9 \%)$ & $34(4.8 \%)$ & $17(8.4 \%)$ & 0.055 \\
\hline Arterial hypertension, $n$ & $687(75.9 \%)$ & $523(74.5 \%)$ & $164(80.8 \%)$ & 0.065 \\
\hline Atrial fibrillation, $n$ & $163(18.0 \%)$ & $115(16.4 \%)$ & $48(23.6 \%)$ & 0.018 \\
\hline Chronic obstructive pulmonary disease, $n$ & $104(11.5 \%)$ & $74(10.6 \%)$ & $30(14.8 \%)$ & 0.097 \\
\hline Coronary heart disease, $n$ & $350(38.8 \%)$ & $249(35.6 \%)$ & $101(49.8 \%)$ & $<0.001$ \\
\hline Chronic renal failure, $n$ & 99 (11.0\%) & $64(9.1 \%)$ & $35(17.2 \%)$ & 0.001 \\
\hline Renal replacement therapy, $n$ & $10(1.1 \%)$ & $8(1.1 \%)$ & $2(1.0 \%)$ & 1.000 \\
\hline
\end{tabular}


replacement of the aortic arch was performed in $22.6 \%$ of elder patients vs. $21.7 \%$ in young patients. The CPB time [144 $\min (113,189)$ vs. $139 \mathrm{~min}(110,183) ; p=0.225]$ as well as the cross-clamping time $[92 \mathrm{~min}(65,127)$ vs. 91 $\min (63,116) ; p=0.348]$ showed no significant difference between old and young patients. Time of circulatory arrest was nearly the same in both groups $[15 \mathrm{~min}(12,18)$ vs.14 $\min (12,17) ; p=0.42]$. Direct cannulation of the ascending aorta (85.6\% in elderly group vs. $78.6 \%$ in young group) was the most performed cannulation strategy (Table 2).

Postoperative data analysis showed no significant difference in inotrope requirement or amount of blood loss during admission in the intensive care unit. The incidence of re-exploration due to bleeding or cardiac tamponade was unexpectedly lower in the elderly group than in the younger group $(3.9 \%$ vs. $7.3 \%, p=0.090)$. The incidence regarding the postoperative cardiac arrhythmia, temporary renal dialysis, prolonged mechanical ventilation, and deep wound infection were significantly higher in the elderly group than in the younger group. The overall hospital stays showed significantly differences between both groups. In our analysis, the elderly group suffered significantly more often from postoperative delirium than the younger group $(24.1 \%$ vs. $9.0 \%, p=<0.001)$. However, postoperative stroke showed no significant difference $(4.9 \%$ vs. $6.0 \%, p=0.569)$. A 30 -day mortality was satisfactory for the elderly group, but significantly higher compared to the younger group $(7.1 \%$ vs. $3.5 \%, p=$ 0.031) (Table 3).

Table 2 Intraoperative course

\begin{tabular}{|c|c|c|c|c|}
\hline & Total & Young group & Elderly group & $p$ value \\
\hline \multicolumn{5}{|l|}{ Surgical procedure } \\
\hline $\begin{array}{l}\text { Interposition graft } \\
\text { alone, } n\end{array}$ & $508(56.1 \%)$ & $380(51.1 \%)$ & $128(63.1 \%)$ & 0.024 \\
\hline $\begin{array}{l}\text { Interposition graft } \\
\text { with partial arch } \\
\text { replacement, } n\end{array}$ & $203(22.4 \%)$ & $159(22.6 \%)$ & $44(21.7 \%)$ & 0.769 \\
\hline $\begin{array}{l}\text { Interposition graft } \\
\text { with total arch } \\
\text { replacement, } n\end{array}$ & $29(3.2 \%)$ & $21(3.0 \%)$ & $8(3.9 \%)$ & 0.501 \\
\hline $\begin{array}{l}\text { Interposition graft } \\
\text { with separated aortic } \\
\text { valve replacement, } n\end{array}$ & $462(51.0 \%)$ & $356(50.7 \%)$ & $106(52.2 \%)$ & 0.706 \\
\hline $\begin{array}{l}\text { Composite graft } \\
\text { replacement of } \\
\text { aortic root with } \\
\text { reimplantation of } \\
\text { coronary arteries, } n\end{array}$ & 149 (16.5\%) & 124 (17.7\%) & $25(12.3 \%)$ & 0.070 \\
\hline $\begin{array}{l}\text { Valve sparing aortic } \\
\text { root replacement, } n\end{array}$ & $63(7.0 \%)$ & $56(8.0 \%)$ & $7(3.4 \%)$ & 0.026 \\
\hline Performed CABG, $n$ & $222(24.6 \%)$ & $164(23.4 \%)$ & $58(28.6 \%)$ & 0.131 \\
\hline Length of surgery, min & $250(203,308)$ & $252(205,313)$ & $240(200,294)$ & 0.187 \\
\hline $\begin{array}{l}\text { Cardiopulmonary bypass } \\
\text { time, min }\end{array}$ & $142(113,187)$ & $144(113,189)$ & $139(110,183)$ & 0.225 \\
\hline Cross-clamp time, min & $92(65,125)$ & $92(65,127)$ & $91(63,116)$ & 0.348 \\
\hline Circulatory arrest, min & $14(12,18)$ & $14(12,17)$ & $15(12,18)$ & 0.419 \\
\hline Temperature, ${ }^{\circ} \mathrm{C}$ & $24 \pm 2$ & $24 \pm 2$ & $24 \pm 2$ & 1.0 \\
\hline $\begin{array}{l}\text { Number of packed red } \\
\text { blood cells, units }\end{array}$ & $2(0,4)$ & $2(0,4)$ & $2(1,4)$ & 0.002 \\
\hline $\begin{array}{l}\text { Number of platelets } \\
\text { concentrate, units }\end{array}$ & $1(0,1)$ & $1(0,2)$ & $1(0,1)$ & 0.753 \\
\hline \multicolumn{5}{|l|}{ Arterial cannulation, $n$} \\
\hline Ascending aorta & $680(80.2 \%)$ & $520(78.7 \%)$ & $160(85.6 \%)$ & \\
\hline Aortic arch & $107(12.6 \%)$ & $93(14.1 \%)$ & $14(7.5 \%)$ & \\
\hline $\begin{array}{l}\text { Transatrial through } \\
\text { the left ventricle }\end{array}$ & $48(5.7 \%)$ & $36(5.4 \%)$ & $12(6.4 \%)$ & \\
\hline Femoral artery & $10(1.2 \%)$ & $9(1.4 \%)$ & $1(0.5 \%)$ & \\
\hline
\end{tabular}


Table 3 Postoperative data and outcomes

\begin{tabular}{|c|c|c|c|c|}
\hline & Total & Young group & Elderly group & $p$ value \\
\hline \multicolumn{5}{|l|}{ Postoperative status } \\
\hline Stable & $325(36.0 \%)$ & $258(36.8 \%)$ & 67 (33.3\%) & \\
\hline Stable with low-dose catecholamines & $533(59.1 \%)$ & $411(58.6 \%)$ & $122(60.7 \%)$ & \\
\hline Stable with high-dose catecholamines & $33(3.7 \%)$ & $22(3.1 \%)$ & $11(5.5 \%)$ & \\
\hline IABP/ECLS with catecholamines & $10(1.1 \%)$ & $9(1.3 \%)$ & $1(0.5 \%)$ & \\
\hline 48-h drainage loss, $\mathrm{mL}$ & $600(400,950)$ & $550(358,900)$ & $600(400,1150)$ & 0.016 \\
\hline Re-exploration for bleeding, $n$ & $59(6.5 \%)$ & $51(7.3 \%)$ & $8(3.9 \%)$ & 0.090 \\
\hline Ventilation time, $\mathrm{h}$ & $17(1231)$ & $17(11,26)$ & $20(15,57)$ & $<0.001$ \\
\hline Tracheotomy, $n$ & $69(7.6 \%)$ & $50(7.1 \%)$ & $19(9.4 \%)$ & 0.293 \\
\hline Pulmonary infection & $58(6.4 \%)$ & $37(5.3 \%)$ & $21(10.3 \%)$ & 0.009 \\
\hline New onset of hemodialysis, $n$ & $48(5.3 \%)$ & $36(5.1 \%)$ & $12(5.9 \%)$ & 0.667 \\
\hline Postoperative atrial fibrillation, $n$ & $140(15.7 \%)$ & $95(13.7 \%)$ & $45(22.6 \%)$ & 0.002 \\
\hline Postoperative delirium, $n$ & $112(12.4 \%)$ & $63(9.0 \%)$ & 49 (24.1\%) & $<0.001$ \\
\hline Postoperative stroke (CT-proofed), $n$ & $52(5.7 \%)$ & $42(6.0 \%)$ & $10(4.9 \%)$ & 0.569 \\
\hline Deep sternal wound infection, $n$ & $12(1.3 \%)$ & $6(0.9 \%)$ & $6(3.0 \%)$ & 0.032 \\
\hline Intensive care unit stay, days & $2(1,4)$ & $2(1,3)$ & $2(1,5)$ & 0.005 \\
\hline Hospital stay, days & $9(7,13)$ & $9(7,12)$ & $10(8,15)$ & 0.002 \\
\hline 30-day mortality, $n$ & $36(4.0 \%)$ & $23(3.5 \%)$ & $13(7.1 \%)$ & 0.031 \\
\hline
\end{tabular}

The multivariate logistic regression analysis pointed out that older age ( $>75$ years, OR $2.799 ; p=0.019$ ), cardiopulmonary bypass time (OR 1.022, $p<0.001$ ), crossclamping time (OR $0.985, p=0.033$ ), and postoperative blood transfusion (OR 4.650, $p=0.006$ ) were independent risk factors for mortality (Table 4).

\section{Discussion}

In the last decades, cerebral tissue protection was the main concern in aortic surgery due to the high susceptibility of the nerve tissue to ischemic adverse effects. As it is known that systemic hypothermia reduces the metabolic tissue rate and consequently protects the brain during cardiac and aortic surgeries, various studies were carried out to investigate the impact of hypothermic circulatory arrest on the neurological outcomes as a result of brain tissue ischemia following aortic surgery [6].

Table 4 The multivariate logistic regression analysis for 30 days mortality. Variables included in the regression analysis: age, EuroSCORE II, aortic aneurysm, aortic calcification, COPD, coronary heart disease, chronic renal insufficiency, additional $\mathrm{CABG}$, and cardiopulmonary bypass time

\begin{tabular}{llll}
\hline & Odds ratio & $\mathrm{Cl}$ & $p$ value \\
\hline Age $>$ 75 years & 2.799 & $1.184-6.616$ & $\mathbf{0 . 0 1 9}$ \\
Cardiopulmonary bypass time & 1.022 & $1.013-1.032$ & $<\mathbf{0 . 0 0 1}$ \\
Cross-Clamp time & 0.985 & $0.972-0.999$ & $\mathbf{0 . 0 3 3}$ \\
Postoperative blood transfusion & 4.650 & $1.550-13.952$ & $\mathbf{0 . 0 0 6}$ \\
\hline
\end{tabular}

The idea of reduction of cerebral metabolic activity and its oxygen consumption in hypothermic circulatory arrest was confirmed in several studies [7, 8]. According to Yan et al., hypothermia was categorized in four groups according to physiological findings into mild $\left(34-28^{\circ} \mathrm{C}\right)$, moderate $\left(28-20^{\circ} \mathrm{C}\right)$, deep $\left(20-14{ }^{\circ} \mathrm{C}\right)$, and profound $\left(<14^{\circ} \mathrm{C}\right)[9]$.

A recent study in 2018 from Stewart et al. on the long-term survival and quality of life after hypothermic circulatory arrest in aortic surgery [77\% were operated under deep hypothermia $\left(\leq 20^{\circ} \mathrm{C}\right)$, and $23 \%$ under moderate hypothermia $\left.\left(20.1{ }^{\circ} \mathrm{C}-28.0^{\circ} \mathrm{C}\right)\right]$ showed that patients undergoing surgery of the thoracic aorta achieve a similar long-term life expectancy and health-related quality of life like those of patients undergoing coronary surgery without hypothermic circulatory arrest. These results justify operative treatment in this high-risk patient population. This study supported the idea of using the hypothermic circulatory arrest as a method of cerebral protection in general [10].

However, the ideal level of temperature to be selected during hypothermic circulatory arrest, besides the technique used for cerebral protection, is still controversial. Several studies suggested that prolonged deep HCA more than $20 \mathrm{~min}$ reduce the postoperative cognitive function of life in patients undergoing thoracic aortic surgery and was associated with poorer neurological outcomes, necessitating the usage of antegrade (ACP) and retrograde cerebral perfusion (RCP) $[2,11]$. On the contrary, other centers do not share the same experience 
regarding the reduction of cognitive functions with prolonged deep HCA in comparison with ACP and RCP. A review from Ziganshin and coworkers comparing cerebral protection techniques stated that those alternatives failed to induce a better survival and stroke rates than deep HCA. Among a large scale of studies between 2007 and 2012, results of deep HCA were very similar, if not better, when compared to other techniques of cerebral protection [12].

A study from the New York Mount Sinai group showed that HCA (14-40 min) did not have an adverse effect on postoperative cognitive function. On the other side, selective cerebral perfusion (39-83 $\mathrm{min}$ ) was one of the significant predictors reducing memory and language tests [13].

Chau et al. stated that HCA is a safe and effective method for cerebral protection against ischemic injury during surgeries of the aorta and aortic arch. HCA is equal and, in some other studies, better than ACP and RCP in terms of minimizing stroke and mortality rates as well as in preserving neurocognitive functions. Its simple application provides an optimal field of visualization as well as suitable for emergency cases, which cannot be offered by either ACP or RCP [3]. Moreover, ACP is not always easy to apply and cannot be used in patients with an extended dissected aortic membrane in brachiocephalic or carotid arteries. RCP leads to inadequate neuroprotection due to the inability of a precise estimation of perfusion volume $[14,15]$.

In our opinion, the tendency to use a higher level of temperature as MHCA more than DHCA to reduce the risk of coagulopathy is increasing nowadays $[9,16,17]$. We considered one of the centers who support this strategy due to the shorter time of rewarming, in order to reduce the duration of surgery and avoid unexpected cognitive adverse outcomes. In 2016, Gong et al. supported our strategy. His study implies the clinical safety and efficacy of MHCA in emergency aortic arch repair, which can provide comparable cerebral and visceral organ protection while decreasing $\mathrm{CPB}$ and aortic crossclamp times without increasing the risk of operative mortality and morbidity [18].

Moreover, a recent study from Kamenskaya et al. aimed to compare the effect of deep HCA $\left(18^{\circ} \mathrm{C}\right)$ vs. moderate $\mathrm{HCA}\left(24^{\circ} \mathrm{C}\right)$ combined with antegrade cerebral perfusion $(\mathrm{ACP})$ in cerebral protection during the surgical treatment of chronic dissection of the ascending aorta and aortic arch. The regional hemoglobin oxygen saturation $\left(\mathrm{rSO}_{2}, \%\right)$ was compared during surgery. Neurological complications were analyzed during the early postoperative period. Moreover, the study assessed the quality of life (QoL) in the long-term postoperative period (1-year follow-up). The study stated that MHCA with ACP during the surgical treatment of the aorta demonstrated higher qualities of cerebral protection, resulting in reduced neurologic complications during the early postoperative period compared to patients who underwent DHCA during surgery [16].

In comparison with our results, we proved that isolated usage of MHCA without ACP could also achieve satisfactory results regarding the postoperative neurological outcomes in older patients. We agreed with those experiences that recommend the isolated application of MHCA, due to its simplicity and ease of application especially if the time of circulatory arrest is not expected to be longer than the average. Moreover, we figured out the relation between the MHCA and the postoperative neurological outcome in old aged patients.

However, that debate had divided the community of cardiovascular surgeons into various camps, each of them supporting one of these techniques according to their experience and preferences $[13,19,20]$.

\section{Conclusion}

Our current analysis reveals that surgical replacement of the ascending aorta using moderate hypothermic circulatory arrest could be applied easily and safely on old aged patients without increasing the risk of neurological complication, even when heavily calcified aorta has to be resected. We encourage the usage of this technique in complexed surgical aortic operation.

\section{Limitations}

The main limitation of this study is its retrospective design. The study is a single-center study and based on a non-randomized analysis of data.

Another limitation is the inability of NIRS to detect other uneventful focal cerebral ischemia, which do not exist in the field of view of the used NIRS.

\section{Abbreviations \\ ACP: Antegrade cerebral perfusion; CABG: Coronary artery bypass grafting; CAM: Confusion assessment method; CT-scan: Computed tomography; MHCA: Moderate hypothermic circulatory arrest; NIRS: Near-infrared spectroscopy; PCP: Postgrade cerebral perfusion; QoL: Quality of life; $\mathrm{rSO}_{2}$, \%: Oxygen saturation; TIA: Transient ischemic attack}

\section{Acknowledgements}

Not applicable.

\section{Authors' contributions}

CF analyzed and interpreted the patient data and was a major contributor in writing the manuscript. AT shared in the design and read and approved the final manuscript. MAS collected and interpreted the patient data with CF, read and critically reviewed the paper, and approved the final manuscript. $\mathrm{TP}, \mathrm{RR}$, and RB shared in the design and idea of the work, read and critically reviewed the paper, and approved the final manuscript. JC made substantial contributions to the concept, design of the work, read, critically reviewed the paper, and approved the final manuscript. AH made substantial contributions to the concept and design of the work, read and critically reviewed the paper, and approved the final manuscript. All authors read and approved the final manuscript. 
Funding

No funding.

\section{Availability of data and materials}

The datasets used and/or analyzed during the current study are available from the corresponding author on reasonable request.

\section{Ethics approval and consent to participate}

The approval for this study was obtained by the local ethics committee "Faculty of Medicine, Christian-Albrechts-University in Kiel" in Germany (D417/17). Informed written consent to participate in the study was provided by all participants at the admission.

\section{Consent for publication}

Not applicable.

\section{Competing interests}

The authors declare that they have no competing interests.

Received: 22 December 2019 Accepted: 14 February 2020

Published online: 30 March 2020

\section{References}

1. Halushka MK, Angelini A, Bartoloni G et al (2016) Consensus statement on surgical pathology of the aorta from the Society for Cardiovascular Pathology and the Association For European Cardiovascular Pathology: II. Noninflammatory degenerative diseases - nomenclature and diagnostic criteria. Cardiovasc Pathol 25(3):247-257. https://doi.org/10.1016/j.carpath. 2016.03.002 Published online 2016 Mar 12

2. Ergin MA, Uysal S, Reich DL et al (1999) Temporary neurological dysfunction after deep hypothermic circulatory arrest: a clinical marker of long-term functional deficit. Ann Thorac Surg 67:1887-1890 discussion 1891-4

3. Chau KH, Ziganshin BA, Elefteriades JA (2013) Deep hypothermic circulatory arrest: real-life suspended animation. Prog Cardiovasc Dis 56:81-91

4. Friedrich I, Simm A, Kötting J, Thölen F, Fischer B, Silber RE (2009) Cardiac surgery in the elderly patient. Dtsch Arzte bl Int 106(25):416-422. https://doi. org/10.3238/arztebl.2009.0416

5. Schoeneich F, Rahimi A, Eide M et al (2012) Transatrial left ventricular cannulation for arterial return in CABG with severe aortic calcification. Thorac Cardiovasc Surg 60:60

6. Luehr M, Bachet J, Mohr F-W, Etz CD (2014) Modern temperature management in aortic arch surgery: the dilemma of moderate hypothermia. Eur J Cardiothorac Surg 45(1):27-39. https://doi.org/10.1093/ejcts/ezt154 Published online 2013 Apr 28

7. Marx JA (2010) Rosen's emergency medicine: concepts and clinical practice, 7th edn. Mosby Elsevier, Philadelphia

8. Ehrlich MP, McCullough JN, Zhang N, Weisz DJ, Juvonen T, Bodian CA et a (2002) Effect of hypothermia on cerebral blood flow and metabolism in the pig. Ann Thorac Surg 73:191-197

9. Yan TD, Bannon PG, Bavaria J et al (2013) Consensus on hypothermia in aortic arch surgery. Ann Cardiothorac Surg 2:163-168

10. Stewart JA, Ilkka VH, Jokinen JJ, Vakkuri AP, Suojaranta RT, Wennervirta J, Salminen U-S (2018) Long-term survival and quality of life after hypothermic circulatory arrest in aortic surgery. Scand J Surg 107(4):322-328. https://doi. org/10.1177/1457496918766719 Epub 2018 Apr 9

11. Immer FF, Lippeck C, Barmettler H et al (2004) Improvement of quality of life after surgery on the thoracic aorta: effect of antegrade cerebral perfusion and short duration of deep hypothermic circulatory arrest. Circulation 110:||250-||255

12. Ziganshin BA, Elefteriades JA (2013) Deep hypothermic circulatory arrest. Ann Cardiothorac Surg 2(3):303-315. https://doi.org/10.3978/j.issn.2225319X.2013.01.05

13. Elefteriades JA (2010) What is the best method for brain protection in surgery of the aortic arch? Straight DHCA. Cardiol Clin 28:381-387

14. Misfeld M, Mohr FW, Etz CD (2013) Best strategy for cerebral protection in arch surgery: Antegrade selective cerebral perfusion and adequate hypothermia. Ann Cardiothorac Surg 2:331-338

15. Perreas K, Samanidis G, Thanopoulos A et al (2016) Antegrade or retrograde cerebral perfusion in ascending aorta and hemiarch surgery? A propensitymatched analysis. Ann Thorac Surg 101:146-152
16. Kamenskaya O, Klinkova A, Chernyavsky A et al (2017) Deep hypothermic circulatory arrest vs. antegrade cerebral perfusion in cerebral protection during the surgical treatment of chronic dissection of the ascending and arch aorta. J Extra Corpor Technol 49:16-25

17. Englum BR, Andersen ND, Husain AM, Mathew JP, Hughes GC (2013) Degree of hypothermia in aortic arch surgery - optimal temperature for cerebral and spinal protection: deep hypothermia remains the gold standard in the absence of randomized data. Ann Cardiothorac Surg 2(2): 184-193

18. Gong M, Ma WG, Guan XL et al (2016) Moderate hypothermic circulatory arrest in total arch repair for acute type A aortic dissection: clinical safety and efficacy. J Thorac Dis 8(5):925-933. https://doi.org/10.21037/jtd.2016.02.

19. Bachet J (2010) What is the best method for brain protection in surgery of the aortic arch? Selective antegrade cerebral perfusion. CardiolClin 28:389401

20. Ueda $Y$ (2010) What is the best method for brain protection in surgery of the aortic arch? Retrograde cerebral perfusion. Cardiol Clin 28:371-379

\section{Publisher's Note}

Springer Nature remains neutral with regard to jurisdictional claims in published maps and institutional affiliations.

\section{Submit your manuscript to a SpringerOpen ${ }^{\circ}$ journal and benefit from:}

- Convenient online submission

- Rigorous peer review

- Open access: articles freely available online

- High visibility within the field

- Retaining the copyright to your article

Submit your next manuscript at $\boldsymbol{\nabla}$ springeropen.com 